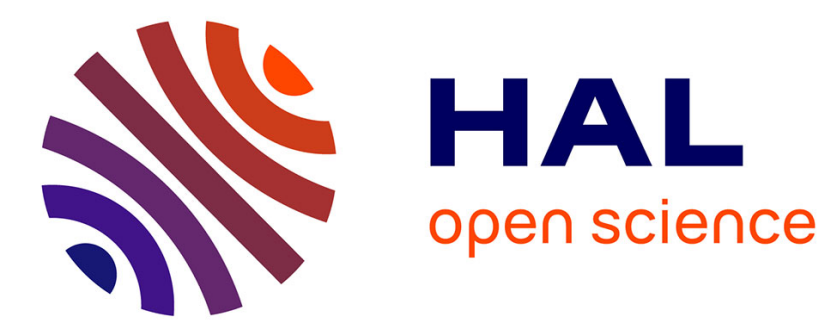

\title{
SIMULTANEOUS OBSERVATION OF OPTOGALVANIC AND OPTOACOUSTIC EFFECTS IN A NEON DISCHARGE
}

Ennio Arimondo, M. Di Vito, K. Ernst, M. Inguscio

\section{- To cite this version:}

Ennio Arimondo, M. Di Vito, K. Ernst, M. Inguscio. SIMULTANEOUS OBSERVATION OF OPTOGALVANIC AND OPTOACOUSTIC EFFECTS IN A NEON DISCHARGE. Journal de Physique Colloques, 1983, 44 (C7), pp.C7-267-C7-270. 10.1051/jphyscol:1983723 . jpa-00223280

HAL Id: jpa-00223280 https://hal.science/jpa-00223280

Submitted on 1 Jan 1983

HAL is a multi-disciplinary open access archive for the deposit and dissemination of scientific research documents, whether they are published or not. The documents may come from teaching and research institutions in France or abroad, or from public or private research centers.
L'archive ouverte pluridisciplinaire HAL, est destinée au dépôt et à la diffusion de documents scientifiques de niveau recherche, publiés ou non, émanant des établissements d'enseignement et de recherche français ou étrangers, des laboratoires publics ou privés. 


\title{
SIMULTANEOUS OBSERVATION OF OPTOGALVANIC AND OPTOACOUSTIC EFFECTS IN A NEON DISCHARGE
}

\author{
E. Arimondo, M.G. Di Vito, K. Ernst ${ }^{+}$and M. Inguscio* \\ Istituto di Fisica Sperimentale, Università di Nopoli, Italy \\ * Dipartimento di Fisica, Università di Pisa, Italy
}

Résumé - On a observé que les signaux optogalvaniques positifs ou négatifs correspondent à un chauffage ou un refroidissement du gaz en détection optoacoustique, et que les deux phénomẽnes ont une dépendance différente en fonction de la pression et du courant de la décharge.

\begin{abstract}
Positive and negative optogalvanic signals appear in the optoacoustic detection as either heating or cooling, and a different dependence on the pressure and the current was observed.
\end{abstract}

In the optogalvanic (OG) effect the current flowing through a discharge tube is modified, under light irradiation, because of the one-step or two-step ionization collisions and the associative ionization. For the energy balance the electrical power flowing through the discharge, is dissipated into the collisional processes. Under light illumination, when the atomic distribution over the energy levels is modified, the number of atomic ions and electrons, the major partners in the collision processes, is modified. Furthermore the electron temperature $T_{e}$ changes because the excitation and ionization collisions depend on the atomic population distribution. As a consequence induced heating or cooling occurs. The question of heating in the optogalvanic effect has been considered previously, mainiy in connection with the selectivity of the atomic excitation following the light absorption by an atomic species. For instance an experimental study on an hollow cathode /1/ has shown that following the excitation of an uranium transition, the population of all the atomic levels is modified and the overall changes is described through a temperature change.

In order to check directly the influence of the heating phenomena in the OG effect, we have modified a standard experimental set-up for $O G$ measurements in a positive column discharge to include provision for the optoacoustic (OA) detection. A side-arm containing a condenser microphone with an internal FET amplifier was added to the glass tube $(20 \mathrm{~cm}$ discharge length, 0.5 internal diameter) containing the discharge, in a position between the grounded cathode and the front glass window. Particular care was taken in starting the tube to avoid discharges towards the microphone. OA signals were obtained also with a microphone, either a piezoelectric or a condenser one, in touch with the external side of the glass tube. Signal from the external microphone was observed also when the microphone was not in touch with the glass tube, but up to several centimeters apart. The experimental observations reported here have been obtained with a quiet discharge, but large optogalvanic as well as optoacoustic signals and very high signal to noise ratio were obtained with the discharge tube operating in a plasma oscillation regime. $O G$ and $O A$ spectra were observed simultaneously on the positive column of the discharge tube

† permanent address : Institute of Experimental Physics, University of Warsaw, Poland 
filled with pure neon gas, under irradiation by light from a commercial argon-pumped broad band dye-laser system operating with Rhodamine $6 G$. By chopping the laser light in the 100-1000 Hz range and processing the $O G$ and $O A$ signals with independent lockin systems, simultaneous recording of the spectra was obtained.

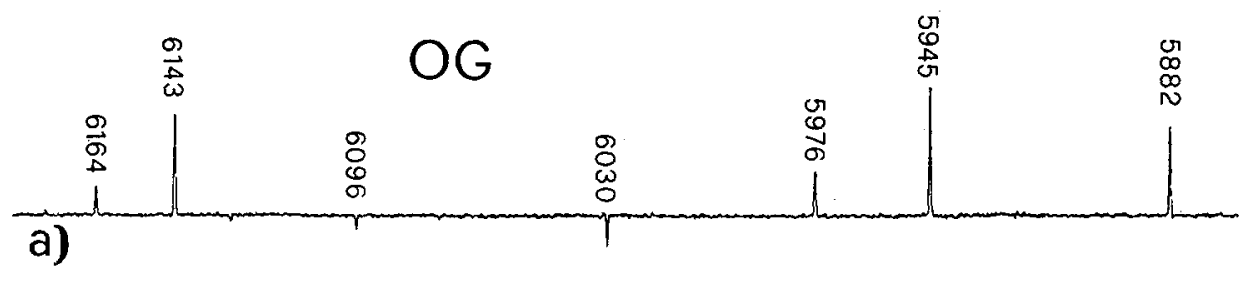

\section{OA}

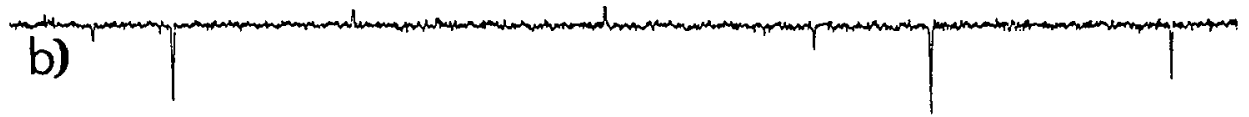

Fig. I - $O G$ and internal microphone $O A$ spectra of a neon discharge in the 5800-6200 $\AA$ range

The Figure I reports the $O G$ (curve a)) and $O A$ (curve b)) spectra recorded in a 0.5 Torr neon discharge at $0.6 \mathrm{~mA}$ current. The $O G$ spectrum presents large signals (corresponding to an increase in the discharge impedance) for the transitions starting from the metastable $1 s_{3}$ and $1 s_{5}$ levels. As characteristic of the low pressure discharges the lines from the $1 s_{2}$ and $1 s_{4}$ non-metastable levels give rise to signals with opposite sign. The striking feature of the $O A$ spectrum in the lower record is the presence of signals with opposite signs, corresponding to heating or cooling of the discharge under light irradiation. Also the external microphone experiences this behaviour with heating and cooling. It should be noticed that the lines with an opposite sign in the $O G$ spectrum produce opposite effects also in the $O A$ spectrum. In particular the absorption lines that starting from the $1 s_{4}$ levels reverse their sign in the $O G$ spectrum depending on the discharge condition, present the same feature in the $O A$ spectrum.

The OA signals of the external and internal microphones show a different behaviour, independently on the transition line. The external microphone produces signals that in intensity and phase have the same behaviour as the $O G$ signal. The internal microphone produces $O A$ signals that change in intensity and phase in reference to the $O G$ signals when the current and the pressure in the discharge are modified. For instance Fig. 2 reports the behaviour of the $O G$ signal and the $O A$ signal obtained with the internal microphone for irradiation of the discharge at the $5945 \AA 1 s_{5}-2 p_{4}$ Tine as a function of the current in the discharge. The plots a) and b) correspond to 2.2 and 0.5 Torr respectively. It may be noticed that both the $O G$ and $O A$ signals decrease 


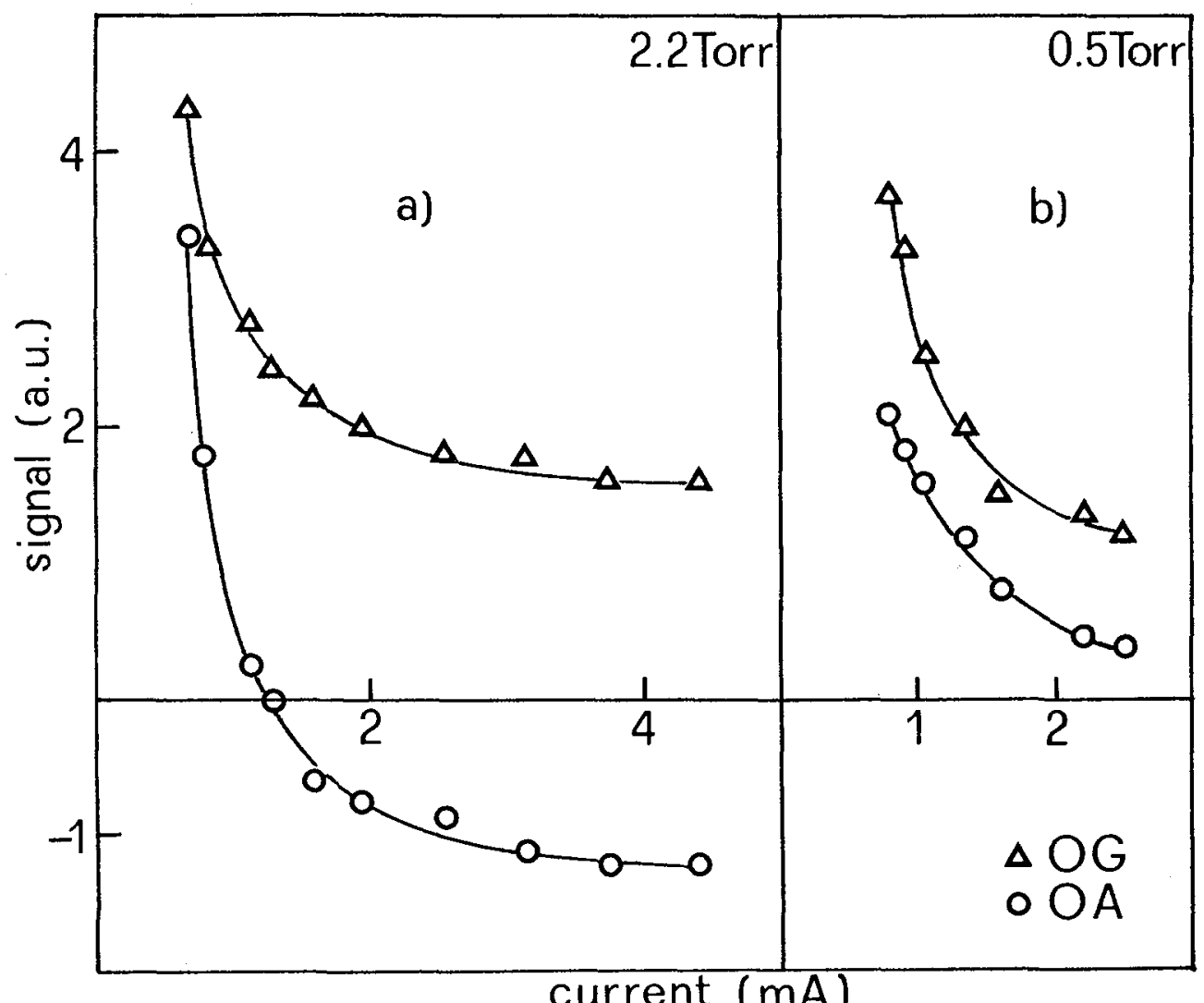

Fig. 2 - The $O G$ signal and the internal microphone $O A$ signal versus the current in the discharge at different pressures.

with the current, but the OA signal has also a sign reversal, i.e. a change from heat ing to cooling, or viceversa depending on the transition line. Moreover, the position of intersection point corresponding to no OA signal shifts to higher current values with decreasing the pressure.

The OG signal, following the theoretical treatment of ref. $/ 2 /$, depends on the light -induced change $\Delta \boldsymbol{i}$ in the current flowing through the discharge. For the energy balance the power $P=7 i E, I$ being the discharge length and $E$ the electric field, is dissipated into the elastic and inelastic collisions. In the elastic collisions of the electron with the neutral atoms, the major components of the gas discharge, a transfer of kinetic energy occurs. In the inelastic collisions, of the first and second kind or the ionizing ones, the electron kinetic energy is modified for amounts equal to the atomic transitions. If the one-step and two-step ionizing inelastic collisions give rise to the $O G$ effect in neon, the elastic collisions determine the gas temperature and the pressure wave experienced by the microphone. Following ref. /3/ the energy balance for a positive column discharge may be written

$$
P=1 i E=7.85 \cdot n_{e} \sum_{m} D_{a m}\left(E_{m I}+5 k \cdot T_{e}\right)
$$

where $n_{e}$ is the electron density along the axis of the discharge tube, $D_{a m}$ the am- 
bipolar diffusion coefficient for the $m$ atomic state, $E_{m} I$ the energy required to ion ize the $m$ state and $T_{e}$ the electron temperature. In the right side of Eq. (1) the $\mathrm{kT}_{e}$ term describes the energy dissipated in the elastic collisions and the $E_{m I}$ term takes into account the inelastic processes.

Under light irradiation the kinetic energy is modified by the $\Delta n_{e}, \Delta D_{a m}$ and $\Delta T_{e}$ changes. However, the proper determination of these changes can be derived only through a solution of the rate equations governing the atomic population and the electron and ion production. In Eq. (1) the change in the total energy dissipated in the discharge may be written

$$
\Delta \mathrm{P}=(\mathrm{TE}-\mathrm{Zi}) \Delta \mathbf{i}
$$

with $Z$ being the ballast resistance, when the voltage supply across the ballast resist ance and the discharge tube is considered constant. The light-induced power dissipated in the elastic collisions i.e. in the gas heating, is obtained as the difference between the power in Eq. (2) and the power due to inelastic collisions. The total dissipated power expressed by $E q .(2)$ is proportional to the $\Delta i$ change, i.e. to the OG signal. The $O A$ signal results from the difference of a term whose behavjour we don't know exactly. The expression for the dissipated power of Eq. (2) may explain the general trend of the internal OA signal as a function of the current reported in Fig. 2. In effect $\Delta i$ may be derived from the simultaneous OG observation. The term in the parenthesis of Eq. (2) decreases and reverses sign increasing the current because the electric field $E$ is nearly independent of the current. Increasing $i$ the dissipated power $\triangle P$ has a behaviour similar to the internal OA signal, but the current $i_{0}$ corresponding to $\triangle P=0$ and derived from measurements of $1, E, Z$ and $i$ is not equal to that measured experimentally. However, the OA signal depends on the difference between $\Delta P$ and the power of the inelastic collisions. The presence of this difference with the second term nearly independent of $i$ could fit the observed behaviour by shiffing io to a smaller value.

The external OA signal does not follow the internal one and it cannot be fitted by the total power $\triangle \mathrm{P}$ of $\mathrm{Eq}$. (2). It has the same behaviour as the $\mathrm{OG}$ signal. Thus it may be explained by different mechanism, but so far we have not been able to give an explanation for the different behaviour of the internal and external OA signals.

The temperature rise measured in ref. (1) through the fluorescent emission from high lying states under resonant irradiation of the positive column provided information on the distribution of internal atomic level which are excited through inelastic collisions. The present experiment determines the enery change in the kinetic degrees of the freedom of the atoms. If on a long-time scale a thermal equilibrium should exists between internal and center-of-mass degree, it is not clear whether in the discharge conditions of these experiments the thermal equilibrium is reached. For instance our observations of light induced thermal cooling should be compared to the temperature change measured under the same conditions on the fiuorescent light. For what concerns the optoacoustic signal it should be noticed that our observations are referred to states lying on the energy scale much higher than in usual optoacoustic experiments. In effect the mechanisms leading to the OA signals in our experiment are very different from those of typical optoacoustic detections, where a direct transfer from internal to kinetic energy occurs. In our case the phenomenon is rather based on the change of the electron and ion concentration because of the atomic internal excitation and the change in the kinetic energy in originated from the collisions by those electrons and ions.

(1) - DREZE C., DEMERS Y., GAGNE' J.M., J. Opt. Soc. Am. 72 (1982) 912

(2) - LAWLER J.E., Phys. Rev. A22 (1980) 1025

(3) - PEPPER D.M., IEEE Journ. of Quantum Electron. QE-14 (1978) 971 